\title{
TOLERÂNCIA À DESSECAÇÃO EM SEMENTES
}

\author{
Claudio José Barbedo' \\ Júlio Marcos Filho ${ }^{2}$
}

Recebido em 17/03/98. Aceito em 8/06/98

\begin{abstract}
RESUMO - (Tolerância à dessecação em sementes). São apresentadas algumas considerações sobre a tolerância das sementes à dessecação, analisando-se os principais trabalhos desenvolvidos com sementes ortodoxas e recalcitrantes. São levantados aspectos considerados importantes no entendimento desta tolerância, como as fases de desenvolvimento e de germinação das sementes, a participação do ácido abscísico, do DNA, de RNAs, de proteínas e de açúcares, as propriedades da água, os radicais livres e particularidades das sementes recalcitrantes. São feitas considerações quanto a perspectivas de ação na área.
\end{abstract}

Palavras-chave - recalcitrante, armazenamento, conservação de sementes

\begin{abstract}
Desiccation tolerance on seeds). Some comments on desiccation tolerance of seeds are presented, with analysis of the main works carried out with orthodox and recalcitrant seeds. It was analysed the aspects that are considered important on this tolerance, as seed developing and germination stages, abscisic acid. DNA. RNAs, proteins, sugars, water properties, free radicals and particularities of recalcitrant seeds. Some action perspectives on this issue are presented.
\end{abstract}

Key words - recaicitrant, storage, seed conservation

\section{Introdução}

Durante o período de formação e maturação das sementes, a água assume papel crucial, atuando inicialmente na expansão e divisão celular e, posteriormente, como veículo para os produtos da fotossíntese que farão parte dos tecidos da semente ou serão armazenados para futura utilização nas fases iniciais da germinação. Assim, até o final do desenvolvimento, o teor de água das sementes permanece elevado, normalmente acima de 30 a $40 \%$ do peso úmido. Ao final da maturação, dois tipos de comportamento podem ser observados quanto ao teor de água das sementes: no primeiro, verificado na maioria das sementes ortodoxas, há rápida redução no teor de água até vạlores próximos a 10\%, variando em função da espécie, o que torna o ambiente na semente impróprio à germinação

Instituto de Botânica, C. Postal 4005, CEP 01061-970, São Paulo, SP

ESALQ, USP, Av. Pádua Dias 11, C. Postal 9, CEP 13418-900. Piracicaba, SP, Brasil. Bolsista do CNPq 
pela falta de água disponível (quiescência). No segundo, verificado na maioria das sementes recalcitrantes, o teor de água permanece elevado e, uma vez que as sementes nesta fase já estão completamente formadas, inicia-se o processo germinativo, o que algumas vezes ocorre ainda na planta-mãe (viviparidade). As sementes ortodoxas, geralmente, não só toleram a dessecação mas, provavelmente, dependem dela para redirecionar os processos metabólicos do desenvolvimento em direção à germinação. Em contraste, as recalcitrantes não apenas são independentes dessa secagem para adquirir a capacidade germinativa, como ainda apresentam limites de tolerância à dessecação.

Essa diferença no comportamento das sementes pode ser considerada como resultado do processo de seleção natural, em concordância com as condições ambientais em que a espécie se desenvolveu. As sementes ortodoxas, que atualmente correspondem à grande maioria das espécies cultivadas, provavelmente necessitaram, durante seu processo de seleção, atravessar períodos inadequados ao desenvolvimento das plântulas; assim, as sementes que germinaram logo que seu processo de formação e maturação havia sido concluído, produziram plântulas incapazes de sobreviver às condições adversas. Foram selecionadas, desta forma, as plantas cujas sementes germinavam apenas quando as condições do meio fossem favoráveis ao desenvolvimento das plântulas. O baixo teor de água das sementes, neste caso, além de limitar a germinação, foi fundamental para evitar a deterioração das mesmas pelo ataque da micro ou mesofauna.

Por outro lado, o ambiente no qual as sementes recalcitrantes foram selecionadas apresentava, provavelmente, condições para o desenvolvimento das plântulas ao longo de todo o ano. Assim, ou as sementes germinavam logo após sua queda das árvores, ou não sobreviveriam à concorrência com sementes de outras espécies. A perda de água ao final da maturação, neste caso, acrescentaria a dependência por mais um fator externo, ou seja, a presença de água suficiente para iniciar o processo germinativo. Além disso, armazenadas secas no solo, as sementes caminhariam para a deterioração ou para a germinação sob condições desfavoráveis ao desenvolvimento das plântulas. A perpetuação da espécie, desta forma, seria prejudicada.

Que mecanismos estariam envolvidos na tolerância à dessecação e que diferenças bioquímicas ou fisiológicas seriam responsáveis pelas diferenças de comportamento entre os dois tipos de sementes?

A maioria das espécies cultivadas, desde os tempos mais remotos da agricultura, enquadra-se na categoria das ortodoxas e, desta forma, a etapa de secagem ao final do desenvolvimento da semente sempre foi considerada como padrão. A maior tolerância à dessecação destas sementes, em relação às recalcitrantes, foi característica vantajosa e muito bem empregada pelo homem, na produção agrícola. Entretanto, mais recentemente, quando se passou a estudar com maior profundidade os ecossistemas tropicais, principalmente os silvícolas, foi-se verificando que o número de espécies com sementes recalcitrantes era alto.

Nos últimos anos, vários estudos começaram a ser realizados visando comparar a diferença entre o comportamento de sementes recalcitrantes e ortodoxas, principalmente nos aspectos fisiológicos e bioquímicos, incluindo a tolerância à dessecação (Berjak et al. 1990; Leprince et al. 1993; Ooms et al. 1993; Neves 1994; Kermode 1997). 
O estudo da tolerância ou sensibilidade à dessecação, que agora não mais se limita às espécies de sementes recalcitrantes, vem trazendo importantes informações ao melhor conhecimento dos processos biológicos que ocorrem na semente. Nesta revisão, concentram-se e discutem-se informações de literatura, com o intuito de esclarecer aspectos de alguns dos fatores formadores de grupos distintos de sementes quanto à tolerância a dessecação.

\section{Fases de desenvolvimento e germinação e suas relações com a desidratação}

Para grande parte das espécies vegetais, o desenvolvimento da semente só é considerado completo após o período de secagem. Sementes de várias espécies permanecem dormentes, se o período de secagem for suprimido.

O desenvolvimento das sementes ortodoxas pode ser dividido em duas fases (Bewley \& Black 1985); a fase inicial, quando a secagem é letal, e a fase subseqüente, que vai até o final do desenvolvimento da semente, em que a mesma pode ser tolerante à dessecação, ou seja, mantém a capacidade de germinar quando desidratada e reidratada. Três fases são reconhecidas (Jiang \& Kermode 1994), considerando-se o estádio fisiológico de desenvolvimento das sementes. O primeiro estádio corresponde à histodiferenciação, onde o zigoto unicelular sofre sucessivas divisões mitóticas seguidas de diferenciação para formar o eixo embrionário e o(s) cotilédone(s), além do desenvolvimento do endosperma triplóide. Segue-se, então, a fase de expansão celular e deposição de reservas nas células. O estádio final (sementes ortodoxas) corresponde à secagem; há redução do metabolismo, com a passagem do embrião para o estádio metabolicamente inativo ou quiescente. Mesmo nesta forma de divisão, há dois períodos distintos durante o desenvolvimento da semente, quando se considera apenas a secagem: intolerante (primeira fase e parte da segunda) e tolerante (parte da segunda fase e toda a terceira fase) à dessecação.

$\mathrm{O}$ conhecimento das fases de intolerância e de resistência à dessecação são fundamentais para o entendimento dos mecanismos controladores dos processos de formação/maturação de sementes e dos processos envolvidos na germinação.

O desenvolvimento da semente e a germinação são estádios físiológicos distintos no ciclo de vida da planta e mostram diferenças marcantes. $\mathrm{O}$ metabolismo durante o desenvolvimento da semente é predominantemente anabólico, com massivo processo de síntese e deposição de reservas de polímeros nos tecidos. Já na germinação, há mobilização destas reservas e são observadas mudanças qualitativas e quantitativas nas enzimas catabólicas. Os produtos deste processo degradativo são utilizados como substrato e fonte de energia para o desenvolvimento das plântulas. Esta distinção entre as duas fases implica na existência de uma chave (switch) para efetuar a transição (Jiang \& Kermode 1994).

Esta chave, provavelmente relacionada com a secagem, foi observada em sementes de feijão (Dasgupta \& Bewley 1982) e de soja (Rosenberg \& Rinne 1989). Estes autores demonstraram o drástico redirecionamento no metabolismo da semente que, quando amadurecida sob desidratação controlada, apresentou paralisação na formação de proteínas de reserva, acompanhada de hidrólise dos polipeptídeos armazenados. As 
sementes não submetidas à desidratação controlada continuaram a sintetizar proteínas de reserva. A secagem, então, pode modificar o padrão da síntese protéica, reduzindo a produção de RNAs-m no eixo embrionário, relacionados com a formação de proteínas envolvidas no desenvolvimento da semente, chegando, inclusive, a cessar a produção destes RNAs-m (Bewley \& Black 1985). Enquanto isso, a produção de RNAs-m relacionados aos processos germinativos é ativada. Enzimas associadas exclusivamente a processos pós-germinativos têm sua produção induzida pela secagem da semente durante seu processo de desenvolvimento/maturação.

É fundamental, porém, que a dessecação seja controlada; há diferença entre a secagem rápida e a secagem lenta. A secagem lenta de sementes imaturas de soja, por exemplo, resultou em sementes viáveis, com degradação de clorofila e formação de enzimas específicas da germinação, enquanto a secagem rápida resultou em sementes inviáveis, de coloração verde e sem formação das enzimas de germinação (Adams et al. 1983).

O comportamento dos embriões imaturos, extraídos das sementes com ou sem subseqüente secagem, no início do desenvolvimento, pode ser similar entre si e em relação ao da semente madura. Posteriormente, porém, são verificadas diferenças (Kermode \& Bewley 1988). Nas sementes não dessecadas durante o desenvolvimento, o tecido circunscrito ao embrião inibe sua germinação, mantendo o metabolismo de desenvolvimento, enquanto nas sementes dessecadas (natural ou artificialmente) há estímulo para a mudança de fase, do desenvolvimento à germinação, por este mesmo tecido. Em algumas sementes pode-se, até, induzir a germinação de seu eixo embrionário, sem a redução do teor de água, porém não necessariamente ocorrerá o desenvolvimento posterior das plântulas oriundas deste processo. Este desenvolvimento posterior continuaria sendo dependente daquela redução no teor de água (Rosenberg \& Rinne 1986). Kermode \& Bewley (1985a) já haviam observado, em sementes de mamona, que apenas a partir da metade do ciclo do desenvolvimento as mesmas adquiriram a tolerância à dessecação, ou seja, quando ainda não havia ocorrido a maioria dos eventos (deposição de reservas e secagem natural). Tal tolerância só foi obtida próximo à fase de maturação, o que também foi observado em sementes de feijão-fava, lentilha, grão-de-bico, tremoço-branco, soja e ervilha (Ellis et al. 1987). O§ autores concluíram, então, que a secagem provavelmente atua nos processos finais de desenvolvimento, preparando a semente para a germinação e para o crescimento da plântula.

Assim, algumas questões importantes estão sendo formuladas com relação aos processos envolvidos na embriogênese e na germinação, merecendo destaque duas grandes áreas de estudo. A primeira investiga quais são os fatores ou reguladores que mantêm o embrião na fase de desenvolvimento, evitando sua germinação. A segunda estuda os fatores que estimulam o início da fase de germinação, em detrimento da continuação do processo de desenvolvimento da semente (Jiang \& Kermode 1994). Há, ainda, uma terceira, mais recente, que vem ganhando expressão: em diversas espécies, em nenhum momento do desenvolvimento de suas sementes se verificou tolerância à dessecação. Estas sementes germinam sem necessitar secagem. Apresentam grande dificuldade em sua conservação por não suportarem a redução do teor de água. Estas 
sementes foram, inicialmente, separadas em um único grupo, recebendo a denominação de sementes recalcitrantes.

Este comportamento, diferenciado do encontrado em espécies ortodoxas, ocorre em sementes de Araucaria angustifolia (Espíndola et al. 1994), de Shorea roxburgii, de Hopea odorata, de Mangifera indica, de Symphonia globulifera (Corbineau \& Côme 1988) e de Quercus robur (Gosling 1989). Nesta última, Gosling (1989) verificou que a intolerância à dessecação foi mais pronunciada quando o teor de água era inferior a $40 \%$, indicando o limite crítico, abaixo do qual os danos seriam cada vez maiores para a semente.

É interessante mencionar que a independência de secagem, para a complementação do desenvolvimento da semente, pode ocorrer também em sementes ortodoxas. Em tomate, por exemplo, Berry \& Bewley (1991) retiraram sementes imaturas dos frutos (35 dias após a antese) e mantiveram-nas em meio úmido. Estas puderam germinar e formar plântulas normais.

Os trabalhos mais recentes, abordando as interações entre as fases de formação e a dessecação das sementes, apontam para a probabilidade de que esta última seja fator indiretamente ligado à aquisição da capacidade germinativa, porém não insubstituível. Estes trabalhos também mostram a necessidade de intensificação dos estudos tocantes à dependência do período de desidratação, mesmo em sementes ortodoxas. Além disso, será fundamental, nestes estudos, conhecer os produtos e processos bioquímicos envolvidos, identificando-se a essencialidade e a magnitude de participação de cada um deles. Alguns já vêm sendo estudados e serão abordados adiante.

\section{Participação do ácido abscísico (ABA) na formação e na desidratação das sementes}

Em algumas espécies é possível, ao embrião em desenvolvimento, adquirir a capacidade germinativa naturalmente, sem requerer etapa final de desidratação. Em outras, porém, este fato é verificado quando embriões imaturos são removidos das sementes em desenvolvimento e colocados em meio de cultura. Os embriões continuam acumulando proteínas e, após breve período de quiescência, podem germinar. A aplicação de $\mathrm{ABA}$ nos embriões, nesta fase, impede a germinação e estimula a continuação da síntese protéica, bem como dos demais processos relacionados ao desenvolvimento da semente. $\mathrm{O}$ ambiente que o embrião encontra na planta-mãe favorece o seu desenvolvimento, em detrimento da germinação. Assim, é de se supor que fornecimento constante de $\mathrm{ABA}$, ou de outro composto de similar função, mantenha o embrião num metabolismo favorável ao desenvolvimento e acúmulo de reservas, impedindo sua germinação (Bewley \& Black 1985). Esta ação do ácido abscísico na germinação foi estudada por diversos pesquisadores, como descreveram Paiva \& Oliveira (1995). Com a secagem da semente haveria redução no nível de $\mathrm{ABA}$ ou diminuição da sensibilidade da semente ao seu efeito, permitindo sua germinação após a reidratação.

Tarquis \& Bradford (1992) questionaram a magnitude deste efeito pois observaram, em sementes de alface, que a expressão genética programada para a germinação teve muito mais influência que o efeito da redução nos níveis de $\mathrm{ABA}$. $\mathrm{O}$ efeito do $\mathrm{ABA}$, nesse momento, seria exclusivamente de inibição da germinação (Xu et al. 1990) ou, 
assim como o efeito de estresse hídrico, complementaria a programação genética, estimulando a síntese de proteínas de reserva sempre que a fase de desenvolvimento do embrião e o meio em que se encontra assim o permitam (Xu \& Bewley 1994).

Além da inibição na germinação, o ABA também apresentaria relações com a tolerância à dessecação. Iida et al. (1992) verificaram que embriões somáticos de cenoura tratados com ABA, dessecados e reidratados, tiveram desenvolvimento normal, enquanto os não tratados não sobreviveram após a dessecação. Porém, o estádio de desenvolvimento dos embriões foi crítico para que o fornecimento de $\mathrm{ABA}$ surtisse efeito, assim como a concentração do produto e o tempo de exposição ao mesmo.

Em espécies vivíparas ou em mutantes de espécies não vivíparas, nas quais a semente pode germinar ainda na planta-mãe, verificou-se a presença de apenas 25 a $50 \%$ da concentração normal de ABA ou, em outros casos, a mesma concentração, porém com menor sensibilidade do embrião a esta concentração (Bewley \& Black 1985). Em sementes de Avicennia marina, recalcitrantes, Farrant et al. (1993b) observaram que o conteúdo de $\mathrm{ABA}$ no embrião, durante a fase de acúmulo de reservas, foi proporcionalmente menor que no das sementes ortodoxas, enquanto vários outros reguladores de crescimento continuaram em níveis normais. Este fato poderia, então, associar a concentração de ABA no embrião com a sensibilidade da semente à dessecação. Entretanto, há casos em que não se constatou relação entre a concentração de $\mathrm{ABA}$, a sensibilidade do embrião a este regulador de crescimento e a aptidão da semente em germinar precocemente. Assim, podem existir outros fatores ou substâncias que estejam envolvidos neste processo (Bewley \& Black 1985; Tarquis \& Bradford 1992).

O ABA pode ter, também, efeitos indiretos na resistência à dessecação, como simular o efeito de estresse hídrico nas sementes, produzindo RNAs-m e proteínas que normalmente são sintetizados quando a planta é submetida a esta condição (Mundy \& Chua 1988). Koornneef et al. (1989), em estudos com aplicação de ABA em mutantes de Arabidopsis thaliana, concluíram que a resposta genética ao $\mathrm{ABA}$, no tocante à regulagem da perda de água e à dormência, é complexa e necessita de estudos específicos para cada caso.

$\mathrm{O} \mathrm{ABA}$, além de poder induzir a tolerância à dessecação das sementes, pode influenciar no conteúdo de carboidratos solúveis e na produção de proteínas ligadas à dessecação, relacionados com os processos de dessecação (Bartels et al. 1988; Tetteroo et al. 1994). Em sementes recém-germinadas também se verifica a ação do ABA: duas proteínas, que podem estar relacionadas com a tolerância à dessecação, foram detectadas após a incubação de sementes de pepino em papel de filtro saturado com solução de ABA $10^{-3} \mathrm{M}$ (Bruggink \& Toorn 1995).

Assim, ficam evidentes a importância e a participação do ácido abscísico na formação das sementes atuando, direta ou indiretamente, na prevenção da germinação precoce, na síntese de proteínas e carboidratos e na tolerância à dessecação. Entretanto, ainda não está evidenciada sua essencialidade, bem como as formas específicas de sua atuação, as concentrações, os momentos de maior influência no desenvolvimento, bem como sua participação na aquisição da tolerância à dessecação das sementes. 
DNA, RNAs-m e proteínas associados à dessecação

A síntese protéica é um aspecto importante estudado na dessecação das sementes, bem como nos processos de desenvolvimento e germinação.

Osborne \& Boubriak (1994) verificaram que apenas o DNA das células de embriões tolerantes à dessecação mantinham sua integridade durante a secagem. Porém, o controle da produção de proteínas, ora voltadas ao desenvolvimento da semente, ora à germinação e ao crescimento da plântula, é feito por RNAs-m. Em sementes de feijão e de mamona, a desidratação paralizou a produção de RNAs-m voltados ao desenvolvimento da semente, ao mesmo tempo em que os RNAs-m residuais eram degradados; enquanto isso, eram produzidos RNAs-m associados com a germinação e com o crescimento das plântulas. A dessecação poderia ser pequena, mas era necessária. Sementes retiradas prematuramente da planta-mãe e mantidas em meio úmido, por poucos dias, apresentaram desidratação suave, mas adquiriram a capacidade germinativa, enquanto as colocadas imediatamente na água não germinaram (Bewley et al. 1989).

Em sementes de milho, há série de proteínas encontradas apenas nas fases do desenvolvimento em que o embrião é tolerante à dessecação. Nos estádios em que a germinação precoce é evidente, o embrião pode ainda ser intolerante à dessecação. A tolerância nestas sementes apareceu aos 20-25 dias após a polinização, ou seja, depois que as sementes adquiriram a capacidade germinativa (Bochicchio et al. 1988). Rosenberg \& Rinne (1988) observaram, em sementes de soja, que existem proteínas específicas da fase de desidratação. Quando submetidas à secagem controlada, sementes imaturas amadureceram precocemente, com nova síntese e acúmulo de diversos polipeptídeos não detectados nas sementes que não sofreram secagem. Assim, sementes que não atingiram fase de desenvolvimento que permitisse a formação de proteínas e RNAs-m relacionados com a maturação puderam ter essa formação induzida pela desidratação controlada após a colheita. Estas proteínas são análogas às LEA (Late EmbryogenesisAbundant) proteínas observadas em sementes de algodão por Galau et al. (1986).

Em sementes de Ranunculus sceleratus, houve modificações qualitativas e quantitativas nas LEA proteínas, conforme o estádio de maturação e o grau e duração do estresse hídrico (Wechsberg et al. 1994); em sementes de Avicennia marina, intolerantes à dessecação, não se constataram tais modificações (Farrant et al. 1992a, b).

Proteínas específicas da fase de desenvolvimento das sementes ou específicas da fase de germinação e desenvolvimento de plântulas ocorrem no endosperma de sementes de mamona e podem ser solúveis (Kermode \& Bewley 1985b) ou insolúveis (Kermode et al. 1985); podem ocorrer, também, nos cotilédones (Kermode \& Bewley 1986). A transição da fase de desenvolvimento para a fase de germinação, concluída pela dessecação prematura ${ }_{3}$ é espelhada por mudança no padrão de síntese de proteínas solúveis ou insolúveis dentro do tecido endospermático de reserva, após subseqüente reidratação. A síntese de proteínas solúveis, características da fase de desenvolvimento, cessou após cinco horas de embebição, dando lugar à síntese de proteínas ligadas exclusivamente à germinação e ao desenvolvimento de plântulas. A secagem apresenta, então, função importante no redirecionamento do metabolismo de desenvolvimento de sementes para o de germinação. Também foi pré-requisito para a indução de enzimas 
hidrolíticas essenciais à fase pós-germinativa, ou seja, para o desenvolvimento das plântulas. O mesmo comportamento foi verificado para proteínas insolúveis, com a diferença de que estas só são formadas após a reidratação das sementes dessecadas ou após a embebição das sementes maduras (Kermode \& Bewley 1985b; Kermode et al. 1985). Em cotilédones de sementes de mamona, as proteínas solúveis e insolúveis apresentaram o mesmo comportamento das existentes ou formadas nos tecidos endospermáticos. A dessecação induziu a formação de enzimas envolvidas na quebra de proteínas de reserva e na utilização de lipídios (Kermode \& Bewley 1986).

As proteínas específicas da maturação, que podem estar envolvidas com a tolerância à dessecação, também são observadas em sementes de cevada (Bartels $e$ t al. 1988) que, apesar de serem capazes de germinar aos oito dias após a polinização, são intolerantes à dessecação. A intolerância à desidratação só ocorre após alguns dias. Pelo menos de 25 a 30 proteínas são produzidas ou têm seus níveis aumentado durante o período que leva à tolerância à dessecação, podendo estar envolvidas neste processo.

Entretanto, não só as proteínas ligadas à dessecação podem ser responsáveis pela tolerância à secagem das sementes. Bradford \& Chandler (1992), trabalhando com sementes de Zizania palustris e Oriza sativa, concluíram que a ausência de proteínas ligadas à dessecação, bem como a inabilidade em acumular $\mathrm{ABA}$, aparentemente não são as responsáveis pela intolerância à dessecação. Blackman et al. (1991) também colocaram em dúvida a hipótese da dependência exclusiva a um grupo de proteínas acumuladas nas fases finais da embriogênese (LEA proteínas) para a proteção das sementes maduras dos danos por dessecação pois, em sementes de soja, encontraram proteínas distintas das conhecidas e que foram resistentes à coagulação pelo calor. $\mathrm{O}$ nível destas proteínas apresentou correlação positiva com a tolerância à dessecação, o que levaria a concluir pela essencialidade destas proteínas na tolerância à dessecação. Porém, embriões extraídos de sementes imaturas tiveram tal tolerância induzida prematuramente pela secagem lenta, enquanto sementes mantidas em umidade elevada, pelo mesmo período, não adquiriram esta tolerância, embora em ambos os casos tenha havido formação das LEA proteínas. Assim, os autores concluíram que, apesar de contribuírem, tais proteínas podem não ser suficientes para induzir a tolerância à dessecação. Esta última análise foi obtida também por Blackman et al. (1992), que trabalharam com embriões imaturos de sementes de soja dessecados ou mantidos em elevada umidade relativa. Os primeiros suportaram a secagem e germinaram, enquanto os últimos não conseguiram germinar após a dessecação e reidratação. Em ambos os casos, novamente, houve formação de LEA proteínas.

Elucidando mais ainda a questão, Gee et al. (1994) observaram diferenças na tolerância à dessecação entre espécies do gênero Acer: duas foram intolerantes à dessecação e duas foram tolerantes. As quatro espécies possuem proteínas ligadas à dessecação, o que levou os autores a concluírem que as LEA proteínas não são suficientes para induzir, isoladamente, a tolerância à dessecação, apesar de terem atuação importante neste processo.

É interessante observar que, se não são as principais responsáveis pela aquisição de tolerância à desidratação em sementes, as LEA proteínas devem ter participação fundamental no processo. Em todos os materiais avaliados nas pesquisas mencionadas, 
tais proteínas estavam presentes quando houve tolerância à dessecação, adquirida naturalmente ou sob condições controladas.

\section{Carboidratos envolvidos na tolerância à dessecação}

O estudo de sementes recém-germinadas pode ser utilizado para o entendimento da tolerância à dessecação (Bruggink \& Toorn 1995). Uma das primeiras observações sobre a função de alguns açúcares na tolerância de sementes à dessecação foi feita por Koster \& Leopold (1988), em sementes de soja, ervilha e milho, em que sacarose e outros oligossacarídeos estiveram constantemente presentes durante o estádio de tolerância à dessecação nas primeiras fases da germinação. Quando os oligossacarídeos deixaram de estar presentes, a tolerância à dessecação não mais se manifestou.

Na raiz primária de sementes de milho em germinação, rafinose e sacarose ocorreram em níveis elevados durante o período de tolerância à dessecação, enquanto glicose $\mathrm{e}$ frutose estavam ausentes. À medida que aumentava a intolerância à dessecação, diminuíam os teores de rafinose e sacarose e aumentavam os de glicose e frutose (Leprince et al. 1992).

Durante a desidratação de embriões somáticos de cenoura e alfafa, a tolerância à dessecação não acompanhou as modificações ocorridas no conteúdo dos carboidratos solúveis, sugerindo que os oligossacarídeos e dissacarídeos não são fatores determinantes para a anidrobiose. Entretanto, em secagem lenta, a estaquiose e a sacarose aumentaram com a aquisição da tolerância à dessecação, enquanto os monossacarídeos declinaram, reforçando a idéia de que os carboidratos estão envolvidos na anidrobiose (Tetteroo et al. 1994). Em sementes de couve-flor ocorreu o mesmo fenômeno, ou seja, aumento de glicose e frutose e redução de sacarose e estaquiose com o avanço do processo germinativo e com a conseqüente perda de tolerância à dessecação das sementes (Hoekstra et cl. 1994). Os autores concluíram que a estaquiose não foi pré-requisito para a tolerância à dessecação, mas que a sacarose pode ter sido. A glicose e a frutose podem estar envolvidas nos danos provocados pela dessecação.

Por outro lado, os níveis criticamente baixos de carboidratos solúveis específicos, nas sementes de espécies do gênero Inga, foram considerados fatores fundamentais para a intolerância à dessecação (Pritchard et al. 1995).

Bochicchio et al. (1994) levantaram a hipótese de que dois açúcares estariam envolvidos no processo de aquisição da tolerância à dessecação: a sacarose e a rafinose. Gorecki et al. (1997a, b) verificaram que o acúmulo de oligossacarídeos da família da rafinose correlacionou-se fortemente com a capacidade de sementes de Lupinus luteus germinarem após a dessecação. Obendorf (1997) afirmou que existe um nível crítico desses oligossacarídeos (série rafinósica), abaixo do qual a tolerância à dessecação é comprometida.

A função dos carboidratos no processo de aquisição da tolerância à dessecação provavelmente está ligada à proteção das membranas durante a desidratação. Este fato foi verificado por Chen \& Burris (1990) em sementes de milho submetidas a diferentes processos de secagem. Os autores observaram alta correlação entre a tolerância à 
secagem e a composição de açúcares solúveis, principalmente sacarose e rafinose, sugerindo que estes açúcares teriam importante papel na estabilidade das membranas durante a secagem e a exposição a altas temperaturas. Segundo Ooms et al. (1994), o mesmo efeito desses carboidratos poderia ser obtido com a aplicação de ABA.

Sun et al. (1994), analisando a formação do estado vítreo da água (outra hipótese para explicar a tolerância à dessecação, que será discutida mais adiante) em sementes de soja e de carvalho, reforçaram a idéia de que os açúcares são relevantes nas modificações das fases da membrana, para que a mesma possa reter líquidos cristalinos. Blackman et al. (1992) corroboram a idéia da função dos açúcares no processo de aquisição de tolerância à dessecação, mostrando que sacarose e estaquiose aumentam em eixos embrionários de sementes de soja submetidas à secagem, enquanto nas que permanecem sob elevada umidade relativa, estes açúcares não apresentam alteração em seus teores.

\section{Sementes recalcitrantes e tolerância à dessecação}

Comportamento diferenciado dos descritos até aqui é verificado em sementes recalcitrantes. A classificação destas sementes foi, inicialmente, genérica, avaliando-se apenas a intolerância à dessecação e a baixa longevidade. Atualmente, já se estuda a reclassificação em função de níveis de recalcitrância. Diversos pesquisadores, das mais variadas regiões do mundo, ressaltaram a importância do assunto (Farrant et al. 1988; 1993a; Berjak et al. 1990; Kermode 1990; Horbowicz \& Obendorf 1994; Neves 1994).

A separação clássica ortodoxas $\mathrm{x}$ recalcitrantes passou a ser questionada, procurando-se identificar, com maior consistência, as espécies com sementes recalcitrantes ou os níveis de recalcitrância (Chin et al. 1984; Berjak et al. 1984; Nautiyal \& Purohit 1985a, b, c; Nautiyal et al. 1985; Farrant et al. 1989; Hong \& Ellis 1990); espécies consideradas ortodoxas podem ter diferentes níveis de tolerância à dessecação. Além disso, as sementes podem ser agrupadas por características intermediárias entre as das ortodoxas e as das recalcitrantes (Farrant et al. 1997; Sacande et al. 1997), tornando-se difícil classificá-las em algum grupo, por apresentarem características de ortodoxas, mas possuírem longevidade muito curta (Pence 1996; Vertucci et al. 1996). Porém, classificações à parte, estes estudos vêm contribuindo muito para o entendimento dos processos envolvidos na tolerância à dessecação, dessas sementes, entre outros benefícios.

As diferenças entre estes grupos e, certas vezes, dentro da mesma espécie com sementes desenvolvidas em diferentes condições, têm proporcionado conclusões contraditórias ou, pelo menos, discutíveis. Baseados em dados obtidos em quatro coletas de sementes de Zizania palustris (com teores de água de 74,6, 55,2, 37,0 e $26,8 \%$ ), Probert \& Brierley (1989) concluíram que a secagem inviabilizou a germinação das sementes em qualquer época de colheita, que continuaram intolerantes à dessecação mesmo quando armazenadas embebidas a baixas temperaturas. Berjak et al. (1994) chegaram a conclusões diferentes de Probert \& Brierley (1989). Submeteram as sementes de Zizania palustris à secagem sob temperaturas inferiores a $25^{\circ} \mathrm{C}$, verificando deterioração ultraestrutural mais severa do que quando a mesma foi realizada a $30^{\circ} \mathrm{C}$. 
Esta diferença na tolerância à dessecação sob diferentes temperaturas já havia sido mencionada por Kovach \& Bradford (1992) que, além disso, inferiram que a intolerância. à dessecação das sementes de Z. palustris, na verdade, tratava-se de danos ocorridos na membrana não durante a secagem, mas sim no momento da embebição. Vertucci et al. (1994) verificaram que embriões imaturos de Zizania sp. são mais sensíveis à dessecação que os maduros.

Em sementes de Clausena lansium e Litchi chinensis (também recalcitrantes), entretanto, Fu et al. (1994) verificaram que a tolerância à dessecação aumentou com o decorrer das fases de desenvolvimento. Os autores consideraram, ainda, que os danos causados pela secagem, em sementes recalcitrantes, podem ser atenuados pela excisão do eixo embrionário, seguida por criopreservação.

As diferenças quanto à tolerância à dessecação, entre sementes recalcitrantes, levaram Berjak \& Pammenter (1994) a sugerir classificação considerando o grau de sensibilidade à dessecação, a longevidade em armazenamento hidratado e a sensibilidade ao frio ("chilling"). Estas autoras concordam que a aplicação genérica do termo recalcitrante tem causado muitas confusões. Para evitar tal fato é necessário que se comece a descrever diversas informações importantes, como o habitat natural da espécie, a longevidade das sementes em armazenamento sob condições hidratadas, o teor de água crítico, a sensibilidade ao resfriamento, a existência de dormência e a influência da temperatura durante a secagem, entre outras.

Características importantes em sementes recalcitrantes são a capacidade de germinar imediatamente após a separação da planta-mãe (estas sementes, normalmente, continuam hidratadas até o final do desenvolvimento/maturação) e a presença de açúcares solúveis. Sementes de Quercus robur, por exemplo, consideradas recalcitrantes, adquirem a capacidade germinativa sem a secagem (Finch-Savage et al. 1992). Sementes de Avicennia marina, diferentemente das ortodoxas, permanecem hidratadas e metabolicamente ativas após a abscisão da planta-mãe, podendo iniciar a germinação imediatamente após esta abscisão, graças, entre outros fatores, à disponibilidade de oligossacarídeos que são translocados, prontamente, dos órgãos de reserva para o eixo embrionário (Farrant et al. 1992a, b).

Além dos aspectos já comentados, podem existir outros fatores envolvidos na tolerância à dessecação de sementes, conforme observaram Finch-Savage \& Blake (1994). Estes autores não verificaram relação entre intolerância à dessecação e concentrações de ABA, para sementes de Quercus robur, nem entre esta intolerância e a presença de proteínas de dessecação (LEA proteínas) ou açúcares solúveis, descritos para sementes ortodoxas como responsáveis pela resistência à dessecação. Além disso, os autores observaram grande semelhança entre o desenvolvimento das sementes desta espécie, considerada como recalcitrante (ou intolerante à dessecação), e o de outras consideradas ortodoxas. Still et al. (1994) chegaram a conclusões discordantes de diversos trabalhos citados até aqui quanto à relação entre tolerância à dessecação e níveis de $\mathrm{ABA}$, de açúcares solúveis e de proteínas de dessecação. Estes autores não encontraram evidências da relação entre estes compostos e a tolerância à dessecação em sementes de Zizania palustris. As sementes desta espécie, segundo os autores, foram mais sensíveis à dessecação que as de Oryza sativa. Entretanto, o acúmulo de 
ABA nas sementes de Z. palustris foi duas vezes maior que nas sementes de $O$. sativa, não apresentando relação com o acúmulo de proteínas de dessecação. Sementes de $Z$. palustris, ainda, acumularam cerca de duas vezes mais sacarose que as de arroz, ficando os oligossacarídeos a 1/10 do máximo acúmulo de sacarose. Por fim, os níveis de LEA proteínas foram semelhantes entre as sementes das duas espécies, além de que o maior acúmulo destas proteínas ocorreu após muitas sementes terem iniciado a aquisição de tolerância à dessecação. Os autores concluíram que a sensibilidade à dessecação, em sementes de Z. palustris, não é função da ausência destes fatores.

Steadman et al. (1996), porém, verificaram que existem grandes variações na concentração de açúcares entre diferentes tecidos de sementes intolerantes à dessecação (recalcitrantes). Estes autores observaram que existe forte correlação entre a relação sacarose/oligossacarídeos derivados de sacarose, chegando a classificar as sementes conforme o resultado desta relação.

A síntese destas informações (Finch-Savage et al. 1992; Kovach \& Bradford 1992; Finch-Savage \& Blake 1994; Fu et al. 1994; Still et al. 1994; Vertucci et al. 1994) sugere nível de interferência das variáveis não diretamente estudadas quanto à tolerância à dessecação, impossibilitando atribuir-se a um ou mais dos fatores estudados as diferenças entre sementes ortodoxas e recalcitrantes. Estas informações ressaltam a dificuldade no agrupamento de espécies dentro de uma destas categorias.

Mais consistente é a consideração feita por Finch-Savage (1992), referindo-se ao teor de água crítico, ou seja, aquele abaixo do qual a semente não suporta a secagem. Este teor de água crítico seria o atingido após a perda de toda a água celular livre e explicaria a grande diferença na tolerância à dessecação entre as espécies. Este valor foi estudado em Zizania spp. (Vertucci et al. 1995), em Inga uruguensis (Bilia 1997), em Araucaria angustifolia (Eira et al. 1994), em Euterpe oleracea (Araújo et al. 1994), em seringueira (Pereira 1980; Cicero et al. 1986; Garcia \& Vieira 1994), em Virola surinamensis (Cunha et al. 1992) e em Phoenix loureiri (Araújo \& Barbosa 1992). Os valores do teor de água crítico, nestas espécies, foram de 15 a 38\%, mostrando que esta característica é muito variável de espécie para espécie. Este fato já havia sido observado por Roberts (1973), que mencionou a variação do teor de água crítico, para sementes recalcitrantes, entre 12 e $31 \%$.

É provável, porém, que a conservação de sementes recalcitrantes por longo período, não seja alcançada com processos similares aos utilizados para as ortodoxas, mormente a secagem. Sem a possibilidade, atualmente, de secagem para essas sementes, os pesquisadores, principalmente no Brasil, onde ocorre número elevado de espécies com sementes recalcitrantes, têm buscado formas alternativas de armazenamento, como a manutenção do elevado teor de água das sementes pelo seu acondicionamento em embalagens herméticas e/ou sob baixas temperaturas (Cicero et al. 1986; Pence 1996; Ferraz \& Sampaio 1996; Barbedo 1997; Bilia 1997). Contudo, tal armazenamento freqüientemente conduz, além da deterioração pelo próprio metabolismo da semente, a problemas com microrganismos causadores de processos deteriorativos (Motle et al. 1997), favorecidos pela umidade.

A conservação das sementes recalcitrantes poderia ser obtida com métodos que visassem a paralisação ou a limitação, ao máximo possível, do crescimento do eixo 
embrionário, mantendo-se a semente com fornecimento de água suficiente para evitar sua desidratação abaixo do teor de água crítico. Este procedimento foi realizado em sementes de Melicoccus bijugatus e Eugenia brasiliensis (Goldbach 1979), e em Inga uruguensis (Barbedo 1997), empregando o ácido abscísico como inibidor da germinação.

\section{Outros fatores ligados à dessecação}

\section{Propriedades da água}

A habilidade que as sementes de diversas espécies apresentam em sobreviver à dessecação é resultado de adaptações que previnem a destruição celular durante a perda de água. Quando uma célula não tolerante à dessecação se desidrata, muitos eventos ocorrem: a) os solutos ficam mais concentrados, possivelmente aumentando a taxa de reações químicas destrutivas; b) alguns solutos podem cristalizar, modificando a resistência iônica e o pH da solução intracelular; c) as proteínas começam a desnaturar-se, muitas irreversivelmente; e d) as membranas começam a romper-se, levando à perda da compartimentalização (Koster 1991). A presença de grande quantidade de açúcares solúveis dentro de uma célula pode prevenir estes efeitos danosos da dessecação, formando ligações de hidrogênio e, assim, substituindo a água na manutenção das estruturas hidrofílicas em sua orientação quando hidratada (Crowe et al. 1988, apud Koster 1991).

Koster (1991) verificou que a habilidade das células em tolerar a dessecação pode, em parte, depender da habilidade em vitrificar (glassy state) à temperatura ambiente. Também mostrou que a vitrificação depende de mais de um tipo de açúcar (principalmente a relação sacarose/rafinose), para que não ocorra a cristalização. Então, segundo o autor, a combinação dos açúcares presentes em células tolerantes à dessecação pode permitir a formação do estado vítreo em temperaturas superiores a $0^{\circ} \mathrm{C}$, enquanto a combinação presente em células de sementes sensíveis à dessecação só permitiria a formação do estado vítreo em temperaturas abaixo de $0^{\circ} \mathrm{C}$.

Willians \& Leopold (1989) demonstraram que a temperatura para a formação desse estado vítreo também depende do conteúdo de água do embrião. Afirmaram que o estado vítreo, em função de sua alta viscosidade, protelaria a cristalização de solutos e a total desidratação. A inibição da mobilidade molecular, portanto, restringiria a desnaturação e as reações bioquímicas. A existência do estado vítreo em sementes de milho, segundo os autores, sugere importante função deste estado, de mobilidade molecular restrita, na sobrevivência de sementes dessecadas.

Em sementes de Landolphia kirkii, consideradas recalcitrantes, Berjak et al. (1992) observaram maior tolerância à dessecação nas imaturas, coincidindo com a fase em que a água não congelável estava em seu menor teor, além de apresentar a mais alta entalpia de fusão desta água. Nesta mesma espécie, Pammenter et al. (1991) não observaram diferenças no conteúdo de água congelável das sementes antes e após a desidratação, sendo aquele conteúdo similar ao de sementes tolerantes à dessecação. Concluíram que o conteúdo de água não congelável, isoladamente, não é um fator importante para a sensibilidade à dessecação. Entretanto, quando esta água foi retirada por meio de secagem rápida, houve danos ao embrião, o que não ocorre em sementes tolerantes à dessecação. 


\section{Radicais livres}

Os radicais livres apresentam importante função nos danos causados a moléculas de tecidos vegetais e animais, principalmente quando tecidos amadurecidos são submetidos a estresses ambientais ou a envelhecimento artificial. Em sementes, entretanto, as evidências de que estes radicais livres atuam na perda de viabilidade não são plenamente claras. Apesar disso, é muito provável que as sementes não se diferenciem dos demais tecidos vegetais e ou animais e, assim, sofram ação do oxigênio e de seus radicais livres, influenciando sua mortalidade (Hendry 1993).

Evidências da ação de radicais livres em sementes podem ser verificados quanto à intolerância das mesmas à dessecação, após iniciado o período de embebição para a germinação. Em sementes de milho, há evidências de sequência de eventos em que o oxigênio ativado toma função importante, se não causal, no processo de perda da tolerância à dessecação com o avanço da germinação (Leprince et al. 1990). Hendry et al. (1992) observaram semelhante ação do oxigênio em sementes de Quercus robur, não durante a embebição, mas sim ao final da maturação das sementes. Estas sementes são consideradas recalcitrantes e os autores concluíram que decréscimo na proteção enzimática à ação oxidativa sobre o eixo embrionário, associado à diminuição na concentração de alfa-tocoferol (eventos que ocorreram quando a água é perdida), leva à peroxidação lipídica e à formação de radicais livres no eixo embrionário. Estes eventos podem contribuir para a perda de viabilidade nestas sementes recalcitrantes. A tolerância da membrana aos radicais livres está associada à presença e à quantidade de antioxidantes de lipídios solúveis e, portanto, estes antioxidantes podem contribuir para a tolerância à desidratação em tecidos embrionários da semente (Senaratna et al. 1985). Os antioxidantes foram detectados em eixos embrionários de sementes de soja embebidas por 6 horas (ainda tolerantes à dessecação) em quantidade muito maior que nas embebidas por 36 horas (já sensíveis à dessecação). A ação dos radicais livres, entretanto, merece mais estudos para que se obtenham conclusões mais consistentes.

\section{Considerações finais}

A diferença entre o comportamento das sementes ortodoxas e recalcitrantes, quanto à tolerância à dessecação, é um fato, até aqui, indiscutível. Porém, a identificação dos processos bioquímicos e fisiológicos envolvidos, bem como o nível de participação de cada fator no processo, requerem maior esclarecimento. Há acentuada variação nos resultados, em função de mudanças nos fatores envolvidos (espécie, estádio de desenvolvimento da semente, local de origem da espécie, época de avaliação, condições ambientais durante o desenvolvimento da semente, estado nutricional da planta), o que torna difícil e sujeita a falhas a generalização do fenômeno.

A utilização do termo recalcitrante, inicialmente abrangendo grande número de espécies, consideradas semelhantes entre si, gerou confusão e conflito de resultados. Aparentemente, há mais de um fator envolvido na tolerância ou na sensibilidade à dessecação. Entre estes fatores, estão incluídos: a) o controle de reguladores de crescimento (principalmente o $\mathrm{ABA}$ ); b) o acúmulo de proteínas ao final da maturação (LEA proteínas); c) o balanço entre açúcares๋ solúveis (princapalmente a sacarose, a 
rafinose e a estaquiose); d) a presença de radicais livres; e) as características da água na semente. Nenhum deles, isoladamente, foi capaz de elucidar a tolerância ou intolerância à dessecação, em todas as espécies estudadas; porém, todos eles tinham participação no processo. É provável, portanto, que o gradiente de tolerância à dessecação, observado em alguns trabalhos, seja resultado da combinação destes fatores. Porém, com os resultados obtidos até o momento, tal asserção seria ainda carente de base de dados mais sólida.

Nos estudos relativos à conservação de sementes recalcitrantes, Farrant et al. (1986) e Pammenter et al. (1994) verificaram a possibilidade da ocorrência de estresse hídrico, mesmo quando estas são armazenadas úmidas. Isto porque a semente recalcitrante não cessa o crescimento ao final da sua formação e maturação; no máximo, reduz seu metabolismo a níveis quase imperceptíveis e, talvez, resida neste fato uma das grandes características comuns às espécies com sementes intolerantes à dessecação. Assim, mesmo sob elevados teores de água haveria deficiência hídrica para a fase inicial da germinação, pois a divisão e expansão celular estariam em níveis crescentes. Este fato refletiria um metabolismo tão intenso destas sementes, com tão rápida transição das fases de formação, maturação, embebição, translocação de solutos e retomada de crescimento do eixo embrionário, que não haveria tempo suficiente para o acúmulo das substâncias responsáveis pela tolerância à dessecação, substâncias estas descritas ao longo do presente trabalho.

Mesmo identificando-se, futuramente, todos os fatores envolvidos na tolerância à dessecação, não há garantia de que seria possível submeter sementes recalcitrantes a estes fatores, artificialmente. Esta é uma área muito ampla, ainda, a ser estudada, necessitando muitas informações para sua melhor compreensão.

\section{Referências bibliográficas}

Adams, C. A.; Fjerstad, M. C. \& Rinne, R. W. 1983. Characteristics of soybean seed maturation: necessity for slow dehydration. Crop Science 23: 265-267.

Araújo, E. F.; Silva, R. F. \& Araújo, R. F. 1994. Avaliação da qualidade de sementes de açaí armazenadas em diferentes embalagens e ambientes. Revista Brasileira de Sementes 16: 76-79.

Araújo. E. F. \& Barbosa, J. G. 1992. Influência da embalagem e do ambiente de armazenamento na conservação de sementes de palmeira (Phoenix loureiri Kunth.). Revista Brasileira de Sementes 14: 61-64.

Barbedo, C. J. 1997. Armazenamento de sementes de Inga uruguensis Hook. \& Arn. Tese de Doutorado. Universidade de São Paulo. Piracicaba.

Bartels. D.; Singh, M. \& Salamini. F. 1988. Onset of desiccation tolerance during development of the barley embryo. Planta 175: 485-492.

Berjak, P. \& Pammenter, N. W. 1994. Recalcitrant is not an all-or-nothing situation. Seed Science Research 4: 263-264.

Berjak. P.; Dini, M. \& Pammenter, N. W. 1984. Possible mechanisms underlying the differing dehydration responses in recalcitrant and orthodox seeds: desiccation-associated subcellular changes in propagules of Avicennia marina. Seed Science and Technology 12: 365-384.

Berjak, P.; Farrant, J. M.; Mycock, D. J. \& Pammenter, N. W. 1990. Recalcitrant (homoiohydrous) seeds: the enigma of their desiccation-sensitivity. Seed Science and Technology 18: 297-310.

Berjak. P.; Pammenter, N. W. \& Vertucci, C. 1992. Homoiohydrous (recalcitrant) seeds: developmental status. desiccation sensitivity and the state of water in axes of Landolphia kirkii Dyer. Planta 186: $249-261$. 
Berjak, P.; Bradford, K. J.; Kovach, D. A. \& Pammenter, N. W. 1994. Differential effects of temperature on ultrastructural responses to dehydration in seeds of Zizania palustris. Seed Science Research 4: 111-121.

Berry. T. \& Bewley, J. D. 1991. Seeds of tomato (Lycopersicon esculentum Mill.) which develop in a fully environment in the fruit switch from a developmental to a germinative mode without a requirement for desiccation. Planta 186: 27-34.

Bewley, J. D. \& Black. M. 1985. Seeds: physiology of development and germination. Plenum Press. New York.

Bewley, J. D.; Kermode, A. R. \& Misra, S. 1989. Desiccation and minimal drying treatments of seeds of castor bean and Phaseolus vulgaris which terminate development and promote germination cause changes in protein and messenger RNA synthesis. Annals of Botany 63: 3-17.

Bilia. D. A. C. 1997. Tolerância à dessecação e armazenamento de sementes de Inga uruguensis. Hook. et Arn. Universidade de São Paulo. Piracicaba.

Blackman, S. A.; Wettlaufer, S. H.; Obendorf, R. L. \& Leopold, A. C. 1991. Maturation proteins associated with desiccation tolerance in soybean. Plant Physiology 96: 868-874.

Blackman. S. A.; Obendorf. R. L. \& Leopold, A. C. 1992. Maturation proteins and sugars in desiccation tolerance of developing soybean seeds. Plant Physiology 100: 225-230.

Bochicchio, A.; Vazzana, C.; Raschi, A.; Bartels, D. \& Salamini. F. 1988. Effect of desiccation on isolated embryos of maize. Onset of desiccation tolerance during development. Agronomie 8: 29-36.

Bochicchio, A.; Rizzi. E.; Balconi, C.; Vernieri. P. \& Vazzana, C. 1994. Sucrose and raffinose contents and acquisition of desiccation tolerance in immature maize embryos. Seed Science Research 4: 123-126.

Bradford. K. J. \& Chandler. P.M. 1992. Expression of "dehydrin-like" proteins in embryos and seedlings of Zizania palustris and Oryza sativa during dehydration. Plant Physiology 99: 488494.

Bruggink, T. \& Toorn, P. van der. 1995. Induction of desiccation tolerance in germinated seeds. Seed Science Research 5: 1-4.

Chen. Y. \& Burris, J. S. 1990. Role of carbohydrates in desiccation tolerance and membrane behaviour in maturing maize seed. Crop Science 30: 971-975.

Chin. H. F.; Hor, Y. L. \& Mohd Lassim. M. B. 1984. Identification of recalcitrant seeds. Seed Science and Technology 12: 429-436.

Cicero. S. M.; Marcos Filho, J. \& Toledo, F. F. 1986. Efeitos do tratamento fungicida e de três ambientes de armazenamento sobre a conservação de sementes de seringueira. Anais da Escola Superior de Agricultura "Luiz de Queiroz" 43: 763-787.

Corbineau, F. \& Côme. D. 1988. Storage of recalcitrant seeds of four tropical species. Seed Science and Technology 16: 97-103.

Cunha. R.: Cardoso, M. A.; Santanna, C. A. F. \& Pereira, T. S. 1992. Efeito do dessecamento sobre a viabilidade de sementes de Virola surinamensis (Rol.)Warb. Revista Brasileira de Sementes 14: $69-72$.

Dasgupta, J. \& Bewley, J. D. 1982. Desiccation of axes of Phaseolus vulgaris during development of a switch from a developmental pattern of protein synthesis to a germination pattern. Plant Physiology 70: 1224-1227.

Eira. M. T. S.; Salomão, A. N.: Cunha, R.; Carrara, D. K. \& Mello, C. M. C. 1994. Efeito do teor de água sobre a germinaçầo de sementes de Araucaria angustifolia (Bert.) O. Kıze. - Araucariaceae. Revista Brasileira de Sementes 16: 71-75.

Ellis. R. H.; Hong. T. D. \& Roberts, E. H. 1987. The development of desiceation-tolerance and maximum seed quality during seed maturation in six grain legumes. Annals of Botany 59: 2329.

Espindola, L. S.; Noin, M.; Corbineau, F. \& Côme, D. 1994. Cellular and metabolic damage induced by desiccation in recalcitrant Araucaria angustifolia embryos. Seed Science Research 4: 193-201.

Farrant. J. M.; Pammenter. N. W. \& Berjak. P. 1986. The increasing desiccation sensitivity of recalcitrant Avicennia marina seeds with storage time. Physiologia Plantarum 67: 291-298. 
Farrant, J. M.; Pammenter. N. W. \& Berjak, P. 1988. Recalcitrance - a current assesment. Seed Science and Technology 16: 155-166.

Farrant. J. M.; Pammenter. N. W. \& Berjak, P. 1989. Germination-associated events and the desiccation sensitivity of recalcitrant seeds - a study on three unrelated species. Planta 178: 189-198.

Farrant, J. M.; Berjak, P. \& Pammenter, N. W. 1992a. Proteins in development and germination of a desiccation sensitive (recalcitrant) seed species. Plant Growth Regulation 11: 257-265.

Farrant. J. M.; Pammenter. N. W. \& Berjak. P. 1992b. Development of the recalcitrant (homoiohydrous) seeds of Avicennia marina: anatomical, ultrastructural and biochemical events associated with development from histodifferentiation to maturation. Annals of Botany 70: $75-86$.

Farrant. J. M.; Pammenter. N. W. \& Berjak, P. 1993a. Seed development in relation to desiccation tolerance: a comparision between desiccation-sensitive (recalcitrant) seeds of Avicennia marina and desiccation-tolerant types. Seed Science Research 3: 1-13.

Farrant. J. M.; Berjak. P.; Cutting, J. G. M. \& Pammenter. N. W. 1993b. The role of plant growth regulators in the development and germination of the desiccation-sensitive (recalcitrant) seeds of Avicennia marina. Seed Science Research 3: 55-63.

Farrant. J. M.; Pammenter, N. W.; Berjak, P. \& Walters. C. 1997. Subcellular organization and metabolic activity during the development of seeds that attain different levels of desiccation tolerance. Seed Science Research 7: 135-144.

Ferraz. I. D. K. \& Sampaio. P. T. B. 1996. Métodos simples de armazenamento das sementes de andiroba (Carapa guianensis Aubl. e Carapa procera DC. - Meliaceae). Acta Amazonica 26: 137-144.

Finch-Savage, W. E. 1992. Embryo water status and survival in the recalcitrant species Quercus robur L.: evidence for a critical moisture content. Journal of Experimental Botany 43: 663669.

Finch-Savage, W. E. \& Blake, P. S. 1994. Indeterminated development in desiccation-sensitive seeds of Quercus robur L. Seed Science Research 4: 127-133.

Finch-Savage, W. E.; Clay, H. A.; Blake, P. S. \& Browning. G. 1992. Seed development in the recalcitrant species Quercus robur L.: water status and endogenous abscisic acid levels. Journal of Experimental Botany 43: 671-679.

Fu, J. R.; Jin, J. P.; Peng. Y. F. \& Xia, Q. H. 1994. Desiccation tolerance in two species of recalcitrant seeds: Clausena lansium (Lour.) and Litchi chinensis (Sonn.). Seed Science Research 4: 257 261.

Galau. G. A.; Hughes. D. W. \& Dure, L. 1986. Abscisic acid induction of cloned cotton late embryogenesis-abundant (Lea) RNAs-m. Plant Molecular Biology 7: 155-170.

Garcia. A. \& Vieira, R. D. 1994. Germinação, armazenamento e tratamento fungicida de sementes de seringueira (Hevea brasiliensis Muell. Arg.). Revista Brasileira de Sementes 16: 128-133.

Gee. O. H.; Probert. R. J. \& Coombeer, S. A. 1994. 'Dehydrin-like' proteins and desiccation tolerance in seeds. Seed Science Research 4: 135-141.

Goldbach. H. 1979. Imbibed storage of Melicoccus bijugatus and Eugenia brasiliensis (E. dombeyi) using abscisic acid as a germination inhibitor. Seed Science and Technology 7: 403-406.

Gorecki, R. J.; Piotrowicz-Cieslak, L. B. L. \& Obendorf. R. L. 1997a. Soluble carbohydrates in desiccation tolerance of yellow lupin seeds during maturation and germination. Seed Science Research 7: 107-115.

Gorecki, R. J.; Piotrowicz-Cieslak, L. B. L. \& Obendorf. R. L. 1997b. Soluble sugars and flatulenceproducing oligosaccharides in maturing yellow lupin (Lupinus luteus L.) seeds. Seed Science Research 7: 185-193.

Gosling. P. G. 1989. The effect of drying Quercus robur acorns to differential moisture contents, followed by storage, either with or without imbibition. Forestry 62: 41-50.

Hendry, G. A. F. 1993. Oxygen. free radical processes and seed longevity. Seed Science Research 3: $141-153$. 
Hendry, G. A. F.; Finch-Savage, W. E.; Thorpe, P. C.; Atherton. N. M.; Buckland, S. M.; Nilsson, K. A. \& Seel, W. E. 1992. Free radical processes and loss of seed viability during desiccation in the recalcitrant species Quercus robur L. New Phytologist 122: 273-279.

Hoekstra, F. A.; Haigh. A. M.: Tetteroo, F. A. A. \& Roekel. T. van. 1994. Changes in soluble sugars in relation to desiccation tolerance in cauliflower seeds. Seed Science Research 4: 143-147.

Hong. T. D. \& Ellis, R. H. 1990. A comparison of maturation drying. germination, and desiccation tolerance between developing seeds of Acer pseudoplatanus L. and Acer platanoides L. New Phytologist 116: 589-596.

Horbowicz, M. \& Obendorf, R. L. 1994. Seed desiccation tolerance and storability: dependence on flatulence-producing oligosaccharides and cyclitols - review and survey. Seed Science Research 4: 385-405.

Iida, Y.; Watabe, K.; Kamada. H. \& Harada, H. 1992. Effects of abscisic acid on the induction of desiccation tolerance in carrot somatic embryos. Journal of Plant Physiology 140: 356-360.

Jiang. L. \& Kermode, A. R. 1994. Role of desiccation in the termination of expression of genes for storage proteins. Seed Science Research 4: 149-173.

Kermode. A. R. 1990. Regulatory mechanisms involved in the transition from seed development to germination. Critical Reviews in Plant Sciences 9: 155-195.

Kermode, A. R. 1997. Approaches to elucidate the basis of desiccation-tolerance in seeds. Seed Science Research 7: 75-95.

Kermode, A. R. \& Bewley. J. D. 1985a. The role of maturation drying in the transition from seed development to germination. II. Acquisition of desiccation-tolerance and germinability during development of Ricinus communis L. seeds. Journal of Experimental Botany 36: 1906-1915.

Kermode, A. R. \& Bewley, J. D. 1985b. The role of maturation drying in the transition from seed development to germination. II. Post-germinative enzyme production and soluble proteins synthetic pattern changes within the endosperm of Ricinus communis L. seeds. Journal of Experimental Botany 36: 1916-1927.

Kermode, A. R. \& Bewley, J. D. 1986. The role of maturation drying in the transition from seed development to germination. IV. Protein synthesis and enzime acivity changes within the cotyledons of Ricinus communis L. seeds. Journal of Experimental Botany 37: 1887-1898.

Kermode, A. R. \& Bewley, J. D. 1988. The role of maturation drying in the transition from seed development to germination. Journal of Experimental Botany 39: 487-497.

Kermode, A. R.; Gifford, D. J. \& Bewley, J. D. 1985. The role of maturation drying in the transition from seed development to germination. III. Insoluble proteins synthetic pattern changes within the endosperm of Ricinus communis L. seeds. Journal of Experimental Botany 36: 19281936.

Koornneef, M.; Hanhart, C. J.; Hilhorst, H. W. M. \& Karssen. C. M. 1989. In vivo inhibition of seed development and reserve protein accumulation in recombinants of abscisic acid biosynthesis and responsiveness mutants in Arabidopsis thaliana. Plant Physiology 90: 463-469.

Koster. K. L. 1991. Glass formation and desiccation tolerance in seeds. Plant Physiology 96: 302304.

Koster, K. L. \& Leopold, C. 1988. Sugars and desiccation tolerance in seeds. Plant Physiology 88: 829-832.

Kovach. D. A. \& Bradford. K. J. 1992. Imbibitional damage and desiccation tolerance of wild rice (Zizania palustris) seeds. Journal of Experimental Botany 43: 747-757.

Leprince, O.; Deltour, R.; Thorpe, P. C.; Atherton, N. M. \& Hendry, G. A. F. 1990. The role of free radicals and radical processing systems in loss of desiccation tolerance in germinating maize (Zea mays L.). New Phytologist 116: 573-580.

Leprince, O.; Werf, A. van der; Deltour, R. \& Lambers, H. 1992. Respiratory pathways in germinating maize radicles correlated with desiccation tolerance and soluble sugars. Physiologia Plantarum 85: 581-588.

Leprince, O.; Hendry, G. A. F. \& McKersie, B. D. 1993. The mecanisms of desiccation tolerance in developing seeds. Seed Science Research 3: 231-246.

Motle. N.; Pammenter, N. W.; Berjak, P. \& Frederic, J. C. 1997. Response of the recalcitrant seeds of Avicennia marina to hydrated storage: events occuring at the root primordia. Seed Science Research 7: 169-178. 
Mundy, J. \& Chua, N. 1988. Abscisic acid and water-stress induce the expression of a novel rice gene. EMBO Journal 7: 2279-2268.

Nautiyal, A. R. \& Purohit, A .N. 1985a. Seed viabillity in sal. I. Physiological and biochemical aspects of seed development in Shorea robusta. Seed Science and Technology 13: 59-68.

Nautiyal, A. R. \& Purohit, A. N. 1985b. Seed viabillity in sal. II. Physiological and biochemical aspects of ageing in seeds of Shorea robusta. Seed Science and Technology 13: 69-76.

Nautiyal. A. R. \& Purohit. A. N. 1985c. Seed viabillity in sal. III. Membrane disruption in ageing seeds of Shorea robusta. Seed Science and Technology 13: 77-82.

Nautiyal, A. R.; Thpliyal, A. P. \& Purohit, A. N. 1985. Seed viabillity in sal. IV. Protein changes accompanying loss of viability in Shorea robusta. Seed Science and Technology 13: 83-86.

Neves, C. S. V. J. 1994. Sementes recalcitrantes. Revisão de literatura. Pesquisa Agropecuária Brasileira 29: 1459-1467.

Obendorf, R. L. 1997. Oligosaccharides and galactosyl cyclitols in seed desiccation tolerance. Seed Science Research 7: 63-74.

Ooms. J. J. J.; Léon-Kloosterziel, K. M.; Bartels, D.; Koorneef, M. \& Karssen, C. M. 1993. Acquisition of desiccation tolerance and longevity in seeds of Arabidopsis thaliana. Plant Physiology 102: $1185-1191$.

Ooms, J. J. J.; Wilmer, J. A. \& Karssen, C. M. 1994. Carbohydrates are not the sole factor determining desiccation tolerance in seeds of Arabidopsis thaliana. Physiologia Plantarum 90: 431-436.

Osborne, D. J. \& Boubriak, I. I. 1994. DNA and desiccation tolerance. Seed Science Research 4: $175-185$.

Paiva, R. \& Oliveira, P. D. 1995. The role of abscisic acid during seed precocious germination. Revista Brasileira de Fisiologia Vegetal 7: 175-179.

Pammenter, N. W.; Vertucci, C. W. \& Berjak, P. 1991. Homeohydrous (recalcitrant) seeds: dehydration, the state of water and viability characteristics in Landolphia kirkii. Plant Physiology 96: 1093-1098.

Pammenter, N. W.; Berjak, P.; Farrant, J. M.; Smith, M. T. \& Ross, G. 1994. Why do stored hydrated recalcitrant seeds die? Seed Science Research 4: 187-191.

Pence, V. C. 1996, Germination, desiccation and cryopreservation of seeds of Populus deltoides Bartr. Seed Science and Technology 24: 151-157.

Pereira, J. P. 1980. Conservação da viabilidade do poder germinativo da semente de seringueira. Pesquisa Agropecuária Brasileira 15: 237-244.

Pritchard, H. W.; Haye. A. J.; Wright, W. J. \& Steadman. K. J. 1995. A comparative study of seed viability in Inga species: desiccation tolerance in relation to the physical characteristics and chemical composition of the embryo. Seed Science and Technology 23: 85-100.

Probert, R. J. \& Brierley, E. R. 1989. Desiccation intolerance in seeds of Zizania palustris is not related to developmental age or the duration of post-harvest storage. Annals of Botany 64: 669-674.

Roberts, E. H. 1973. Predicting the storage life of seeds. Seed Science and Technology 1: 499514.

Rosenberg, L. A. \& Rinne, R. W. 1986. Moisture loss as a prerequisite for seedling growth in soybean seeds (Glycine max [L.] Merr.). Journal of Experimental Botany 37: 1663-1674.

Rosenberg, L. A. \& Rinne. R. W. 1988. Protein synthesis during natural and precocious soybean seed (Glycine max [L.] Merr.) maturation. Plant Physiology 87: 474-478.

Rosenberg, L. A. \& Rinne. R. W. 1989. Protein synthesis during rehydration, germination and seedling growth of naturally and precociously matured soybean seeds (Glycine max). Annals of Botany 64: 77-86.

Sacande, M.; Groot, S. P. C.; Hoekstra, F. A.; Castro, R. D. \& Bino, R. J. 1997. Cell cycle events in developing neem (Azadirachta indica) seeds: are they related to intermediate storage behaviour? Seed Science Research 7: 161-168.

Senaratna, T.; McKersie, B. D. \& Stinson, R. H. 1985. Antioxidant levels in germinating soybean seed axes in relation to free radical and dehydration tolerance. Plant Physiology 78: 168-171.

Steadman, K. J.; Pritchard, H. W. \& Dey, P. M. 1996. Tissue-specific soluble sugars in seeds as indicators of storage category. Annals of Botany 77: 667-674. 
Still. D. W.; Kovach. D. A. \& Bradford. K. J. 1994. Development of desiccation tolerance during embryogenesis in rice (Orvza sativa) and wild rice (Zizania palustris). Plant Physiology 104: $431-438$.

Sun. W. Q.: Irving, C. \& Leopold, A. C. 1994. The role of sugar, vitrification and membrane phase transition in seed desiccation tolerance. Physiologia Plantarum 90: 621-628,.

Tarquis. A. M. \& Bradford. K. J. 1992. Prehydration and priming treatments that advance germination also increase the rate of deterioration of lettuce seeds. Journal of Experimental Botany 43: 307-317.

Tetteroo, F. A. A.; Bomal, C.; Hoekstra, F. A. \& Karssen, C. M. 1994. Effect of abscisic acid and slow drying on soluble carbohydrate content in developing embryoids of carrot (Daucus carota L.) and alfalfa (Medicago sativa L.). Seed Science Research 4: 203-210.

Vertucci, C. W.: Crane, J.; Porter, R. A. \& Oelke. E. A. 1994. Physical properties of water in Zizania embryos in relation to maturity status, water content and temperature. Seed Science Research 4: $211-224$.

Vertucci, C. W.; Crane, J.; Porter, R. A. \& Oelke, E. A. 1995. Survival of Zizania embryos in relation to water content, temperature and maturity status. Seed Science Research 5: 31-40.

Vertucci, C.: Crane, J. \& Vance. N. C. 1996. Physiological aspects of Taxus breviflora seeds in relation to seed storage characteristics. Physiologia Plantarum 98: 1-12.

Wechsberg. G. E.: Bray, C. M. \& Probert. R. J. 1994. Expression of 'dehydrin-like' proteins in orthodox seeds of Ramunculus sceleratus during development and water stress. Seed Science Research 4: 241-246.

Willians, R. J. \& Leopold, A. C. 1989. The glassy state in corn embryos. Plant Physiology 89: 977981.

Xu. N. \& Bewley, J. D. 1994. Desiccation and the switch from development to germination. Alfafa embryos can synthesize storage proteins after germination if maturation drying is prevented. Seed Science Research 4: 247-255.

Xu. N.; Coulter, K. M. \& Bewley, J. D. 1990. Abscisic acid and osmoticum prevent germination of developing alfafa embryos, but only osmoticum maintains the synthesis of developmental proteins. Planta 182: $382-390$. 